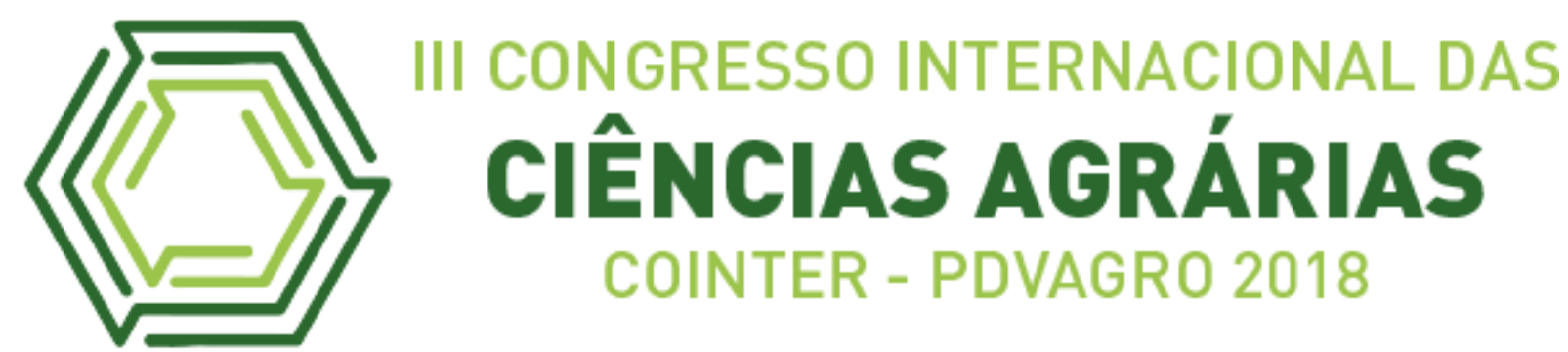

\title{
METABOLISMO DO NITROGÊNIO EM PLANTAS JOVENS DE Clusia grandiflora Splitg. SUBMETIDAS À DEFICIÊNCIA HÍDRICA
}

\section{METABOLISM OF NITROGEN IN YOUNG PLANT OF Clusia grandiflora Splitg.. SUBMITTED TO WATER DEFICIENCY}

Apresentação: Pôster

Jessica Suellen Silva Teixeira ${ }^{1}$; Neire Maria Mendes Ferreira ${ }^{2}$; Alexandre de Moraes Ferreira ${ }^{3}$; Cândido Ferreira de Oliveira Neto ${ }^{4}$; Benedito Gomes Santos Filho ${ }^{5}$

DOI: https://doi.org/10.31692/2526-7701.IIICOINTERPDVAGRO.2018.00568

\section{Introdução}

As espécies arbóreas brasileiras têm despertado o interesse por demonstrarem comportamentos adaptativos que potencializam sua utilização em áreas que não apresentam condições favoráveis para outras espécies, sendo de grande importância silvicultural e econômicos (NASCIMENTO et al., 2011).

Clusia grandiflora Splitg, pertence à família Clusiaceae, é conhecida pelo nome popular de cebola brava, é uma espécie do tipo heliófita, semidecídua e apresenta excelentes qualidades florístico-fitossociológicas, fornecendo sombra, componentes medicinais, biomassa, alimento e proteção física a fauna e ao solo, tem ocorrência na bacia amazônica e apresenta tolerância em habitar principalmente áreas de restinga, cujo solo é rico em areia, possui baixa retenção de água e é pobre em nutrientes (SWAINE, WHITMORE, 1988).

Deste modo, teve-se como objetivo avaliar o metabolismo do nitrogênio em plantas de Clusia grandiflora submetidas à deficiência hídrica.

\section{Fundamentação Teórica}

O estresse hídrico ocorre geralmente de maneira gradual e as plantas tolerantes desenvolveram mecanismos para se adaptarem, durante o estresse a assimilação do nitrogênio é reduzida e as enzimas envolvidas na incorporação de amônia a compostos orgânicos, agem

\footnotetext{
${ }^{1}$ Mestranda em Agronomia, Universidade Federal Rural da Amazônia, jessicassteixeira27@gmail.com;

${ }^{2}$ Doutora em Ciências Agrárias, Universidade Federal Rural da Amazônia,nmferreira@museu-goeldi.br;

${ }^{3}$ Doutor em Ciências Agrárias, Universidade Federal Rural da Amazônia, amferreira@museu-goeldi.br;

${ }^{4}$ Professor Adjunto, Universidade Federal Rural da Amazônia, candido.neto@ufra.edu.br;

${ }^{5}$ Doutor, Universidade Federal Rural da Amazônia, benedito.filho@ufra.edu.br.
} 
como precursores para diferentes metabólitos tendo importante papel na sobrevivência de plantas durante o déficit hídrico (FERREIRA et al., 2006).

Clusia grandiflora Splitg apresenta características de plantas pioneiras, sendo tolerante a ambientes mais hostis com alta irradiância, alta temperatura, baixa umidade do ar e do solo (SWAINE E WHITMORE, 1988). Desperta grande interesse no paisagismo, na recuperação de áreas degradadas, na produção de biomassa, além de possuir propriedades medicinais e valor fitoterápico atribuído a seu látex (VAN DEN BERG, 1984).

\section{Metodologia}

O experimento foi conduzido no período de 03/03/2013 a 30/07/2014, em vasos plásticos de 12 L contendo plantas de Clusia grandiflora Splitg. na casa de vegetação do Laboratório de Solos da Universidade Federal Rural da Amazônia (01 ${ }^{\circ} 28^{\prime}$ 03”'S, 48 29'18'W). As plantas foram submetidas a dois tratamentos hídricos: 1) Controle (C), irrigadas diariamente e 2) deficiência hídrica (DH), com suspensão da irrigação. Foram efetivadas 5 medições, aos 0, 7, 14, 21 e 28 dias, com 4 plantas por tratamentos, perfazendo 40 unidades experimentais.

Os potenciais hídricos antemanhã $\left(\Psi_{\mathrm{am}}\right)$ e do xilema $(\Psi \mathrm{x})$ foram medidos por meio de uma bomba de pressão do tipo Scholander, conforme descrito por Pinheiro et al. (2007). As variáveis bioquímicas analisadas foram: concentrações de nitrato (CN) (CATALDO et al., 1975); atividade da redutase do nitrato (RN) (HAGEMAN; HUCKLESBY, 1971); amônio livre (CAL) (WEATHERBURN, 1967); aminoácidos solúveis totais (AST) (PEOPLES et al., 1989) e proteínas solúveis totais (PST) (BRADFORD, 1976).

$\mathrm{O}$ delineamento do experimento foi inteiramente casualizado, os dados foram submetidos a análise de variância (ANOVA), as médias comparadas pelo teste de Tukey ao nível de 5\%, os gráficos foram elaborados pelo programa Sigma Plot 12.5.

\section{Resultados e Discussões}

O potencial hídrico do antemanhã ( $\psi \mathrm{am})$, as plantas controle e DH obtiveram valores médios, de -0,27 MPa a -0,40 MPa, onde as plantas sob DH apresentaram reduções de 7,30 \%, $25,17 \%, 8,70 \%$ e 9,00 \% respectivamente aos 7, 14, 21 e 28 dias (Figura 1 A). Para o potencial hídrico do xilema foliar ( $\psi \mathrm{x}$ ) foi registrada uma variação de -0,82 Mpa (controle) a 1,48 Mpa (DH) se configurando em decréscimos contínuos nas plantas sob DH de 80,98\%, $6,59 \%, 3,03 \%$ e 14,22 \% aos 7, 14, 21 e 28 dias, respectivamente (Figura 1 B). A redução no 
potencial hídrico foliar das plantas sob estresse hídrico, pode estar atribuída ao aumento da concentração de açúcares e aminoácidos nas folhas, o que aumenta a capacidade de absorção de água das plantas e atenua os efeitos do déficit hídrico (PAGTER et al., 2005),

Figura 1. Potencial hídrico do antemanhã ( $\left.\psi_{\mathrm{am}}: \mathbf{A}\right)$, potencial hídrico do xilema foliar $\left(\psi_{\mathrm{x}:} \mathbf{B}\right)$ de $C$. grandiflora Splitg., submetidas continuamente a $0,7,14,21$ e 28 dias de DH (०) e controle $(\bullet)$. Fonte: Própria.

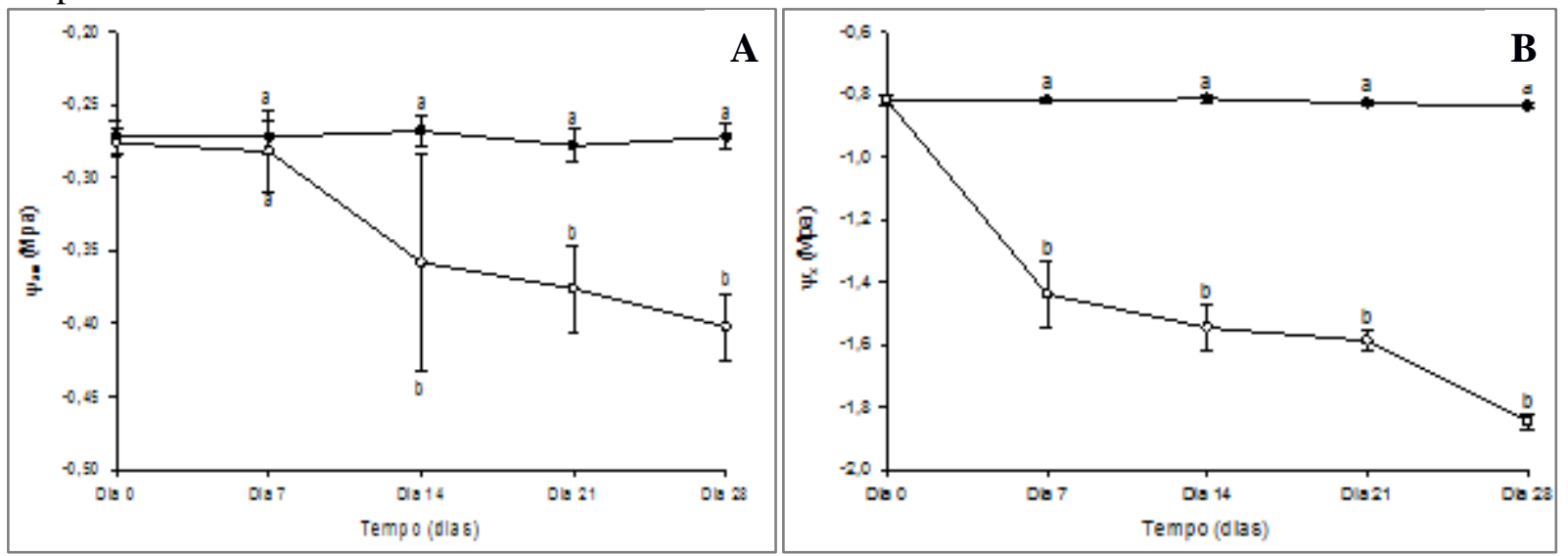

As barras verticais representam o desvio-padrão das médias e as letras representam teste de Tukey $(\mathrm{p}<0,05)$.

Para as concentrações de nitrato os valores médios encontrados no tratamento controle

em folha e raiz foram: 0,47 e $0,66 \mu$ moles de $\mathrm{N0}_{3}{ }^{-} \cdot \mathrm{g}^{-1} \mathrm{MS}$, e no tratamento $\mathrm{DH}$ os valores observados foram: 0,22 e $0,27 \mu$ moles de $\mathrm{NO}_{3}{ }^{-} \cdot \mathrm{g}^{-1} \mathrm{MS}$, representando uma redução de $52,54 \%$ e 59,64\% em folha e raizes em relação as plantas controle (Figura 2 A-folha, B-raiz).

Para as concentrações de redutase do nitrato os valores médios no tratamento controle em folha e raiz se observou os seguintes valores: 0,43 e $0,67 \mathrm{NO}_{2}{ }^{-} / \mathrm{gMF}^{-1} / \mathrm{h}$, e no tratamento $\mathrm{DH}$ os valores observados foram: 1,21 e $1,72 \mu$ moles de $\mathrm{N}_{2}{ }^{-} / \mathrm{gMF}^{-1} / \mathrm{h}$, o que representa UM incremento de $177,9 \%$ em folha e $157,5 \%$ em raiz das plantas DH em relação as plantas controle (Figura $2 \mathrm{C}$ - folha, D - raiz).

Figura 2. Concentração de nitrato em folha e raiz $(\mathrm{CNf}: \mathbf{A}) /(\mathrm{CNr}: \mathbf{B})$ e atividade da redutase do nitrato em folha e raiz (RNf: C) / (RNr; D) de C. grandiflora Splitg., submetidas continuamente a $0,7,14,21$ e 28 dias de DH (०) e controle (•). Fonte: Própria.

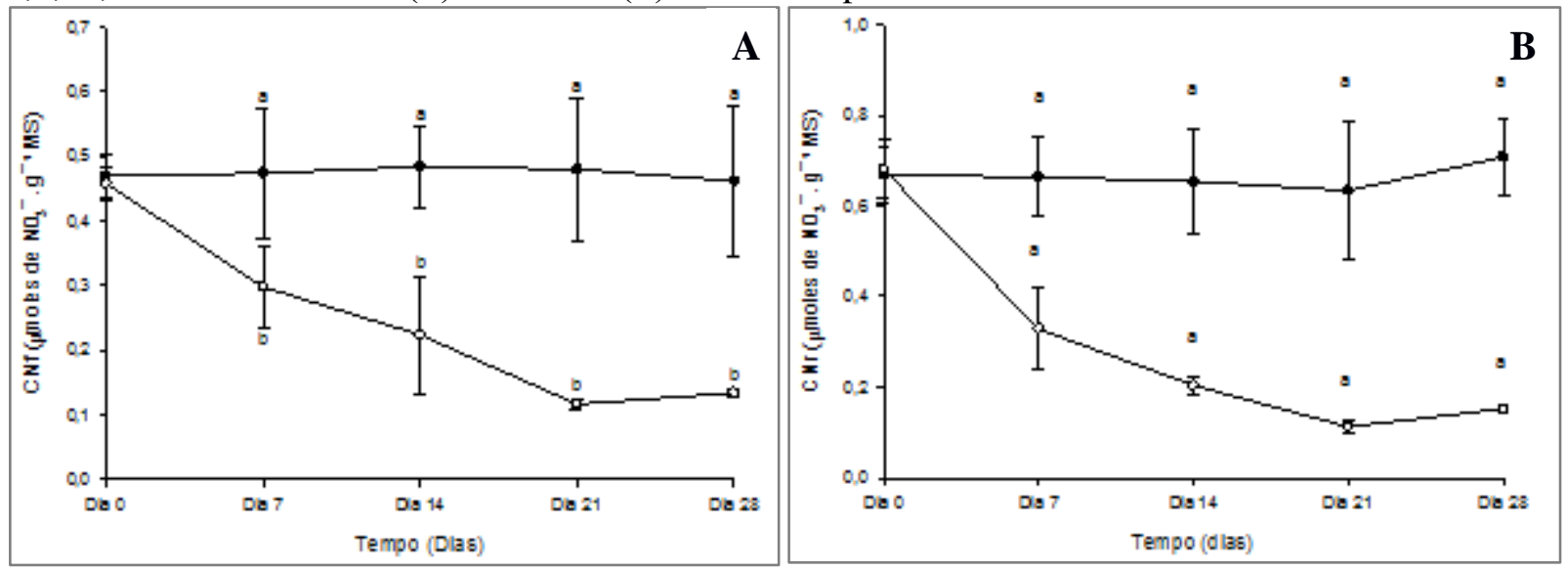



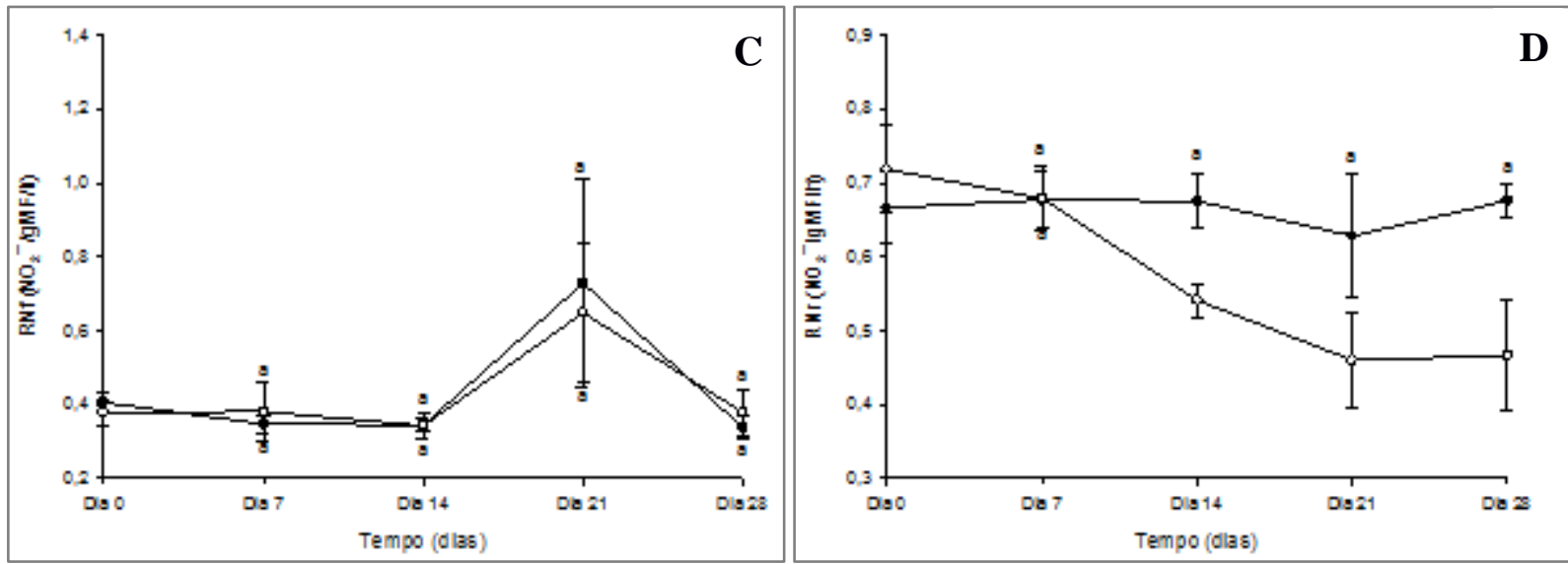

As barras verticais representam o desvio-padrão das médias e as letras representam teste de Tukey $(\mathrm{p}<0,05)$

O estresse hídrico promove a diminuição da absorção de nitrato, do seu transporte e diminui também a atividade da enzima redutase do nitrato que é altamente dependente do seu substrato que é o $\mathrm{NO}^{-3}$ (SHANER; BOYER, 1976).

Para as concentrações de amônio livre os valores médios no tratamento controle em folha e raiz foram: 43,20 e 56,28 mmol de $\mathrm{NH}^{+} / \mathrm{Kg}$ de $\mathrm{MS}$ e no tratamento $\mathrm{DH}$ os valores observados foram: 23,59 e 23,65 $\mathrm{mmol}$ de $\mathrm{NH}^{+} / \mathrm{Kg}$ de $\mathrm{MS}$, o que representa uma redução de 45,39\% em folha e 57,99\% em raiz em relação as plantas controles (Figura 3 A-folha, B-raiz). O decréscimo dos teores de amônio pode ser explicado pela redução da GS, devido à forte relação entre atividade da GS e o acúmulo de íons amônio nos tecidos da planta (CHIEN et al., 2000).

Figura 3. Concentração de amônia em folha e raiz (CALf: A) / (CALr: B) e glutamina sintetase em folha e raiz (GSf: C) / (GSr: D) de C. grandiflora Splitg., submetidas a DH (०) e controle (•). Fonte: Própria.

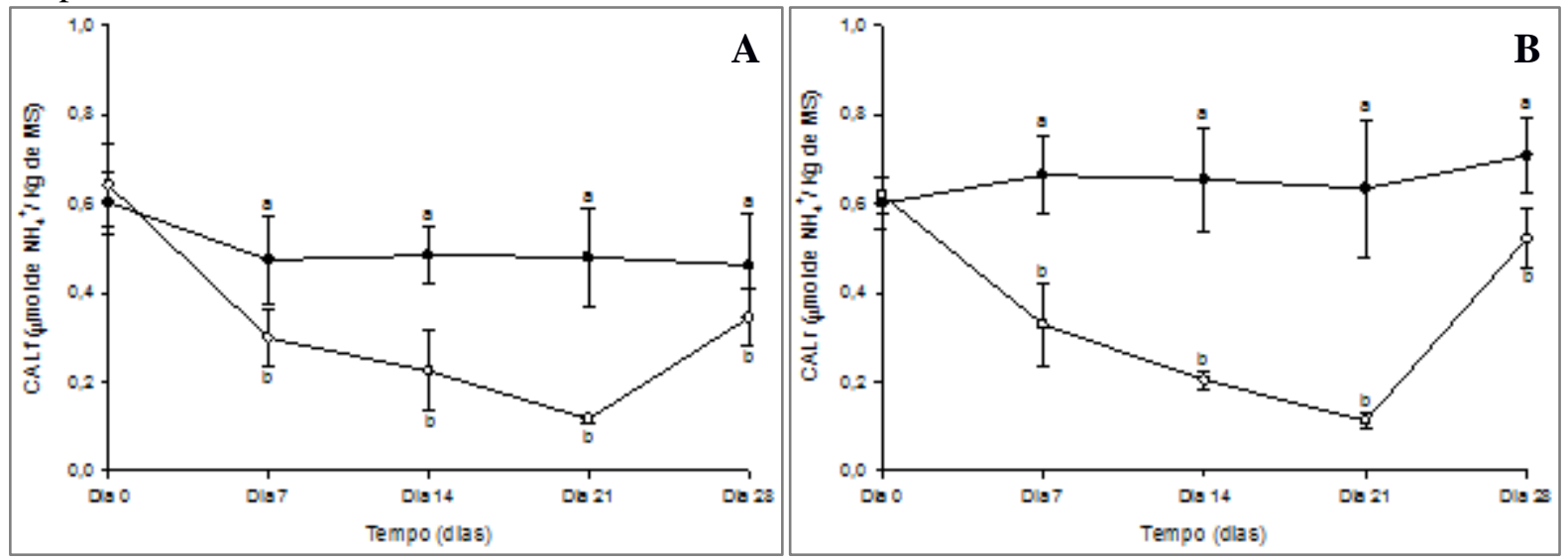

As barras verticais representam o desvio-padrão das médias e as letras representam teste de Tukey $(\mathrm{p}<0,05)$

Para as concentrações de aminoácidos os valores médios no tratamento controle em folha e raiz foram: 51,98 e $36,06 \mu \mathrm{mol}$ de $\mathrm{AA} / \mathrm{g}$. MS, e no tratamento $\mathrm{DH}$ os valores observados foram: 48,16 em folha e 41,10 $\mu \mathrm{mol}$ de AA/g. MS em raiz, que representa 
decréscimo de 7,36\% em folha, e incremento de 13,98\% em raiz em relação as plantas controles (Figura 4: A folha, B-raiz). Esse comportamento pode ser atribuído à alteração do metabolismo do nitrogênio, com redução da síntese de proteína e acúmulo de aminoácidos nas folhas (BRITO et al. 2008).

Para as concentrações de proteínas os valores médios obtidos no tratamento controle em folha e raiz foram: 2,61 e 2,23 $\mathrm{mg}$ de proteína $\mathrm{g}^{-1} \mathrm{MS}$, e no tratamento $\mathrm{DH}$ os valores observados em folha e raiz foram: 1,49 e 1,35 mg de proteína $\mathrm{g}^{-1} \mathrm{MS}$, que representa redução respectivamente de $43,00 \%$ e $39,53 \%$ em relação as plantas controles (Figura 4: C folha, Draiz). Esse resultado mostra que quanto mais baixo o potencial hídrico do solo, maior a atividade das enzimas proteolíticas que são responsáveis pela degradação das proteínas de reserva das plantas, diminuindo os teores destas nas folhas, durante a falta de água.

Figura 4. Concentração de aminoácidos solúveis totais em folha e raiz (ASTf: A) / (ASTr: B) e proteínas solúveis totais em folha e raiz (PSTf: C) / (PSTr: D) de C. grandiflora Splitg., submetidas continuamente a $0,7,14,21$ e 28 dias de DH (०) e controle $(\bullet)$. Fonte: Própria.

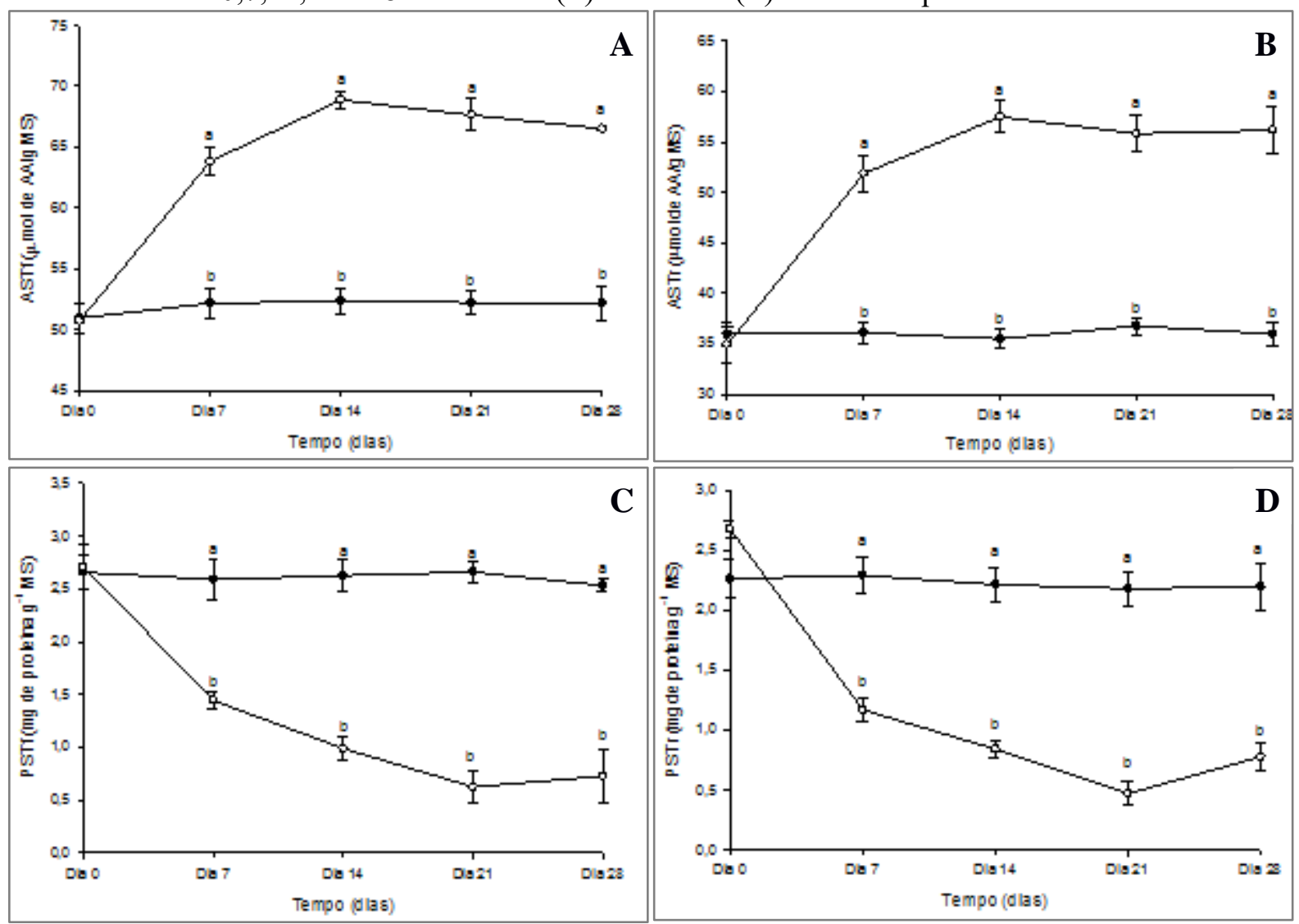

As barras verticais representam o desvio-padrão das médias e as letras representam teste de Tukey $(\mathrm{p}<0,05)$

\section{Conclusão}

A deficiência hídrica do solo por 28 dias em plantas de $C$. grandiflora de 1 ano de idade resultou em aumento significativo dos AST e houve decréscimo da CN, RN, CAL, GS e 
PST como forma de manter o metabolismo e, consequentemente, o crescimento e a sobrevivência das plantas sob estresse hídrico.

\section{Referências}

BRADFORD, M. M. A rapid and sensitive method for the quantitation of microgram quantities of protein utilizing the principle of protein-dye binding. Analytical Biochemistry, v.72, p. 248-254, 1976.

BRITO, L.K.F.L.; SILVEIRA, J.A.G.; LIMA, L. L.F.; TIMÓTEO, A. R. S.;CHAGAS, R. M.; MARCEDO, C. E. C. alterações no perfil de frações nitrogenadas em calosde cana-deaçúcar induzidas por deficit hídrico. Pesquisa Agropecuária Brasileira, Brasília, v.43,n.6, p.683-690, 2008.

CATALDO, D. A.; HAROON, S. L. E; YOUGS, V. L. Rapid colorimetric determination of nitrate in plant tissue by nitration of salicylic acid. Commum Soil Sci. Plant Anal., v. 6, n. 1, p. 71-80, 1975. 104

CHIEN, HG.; LIN, C. C.; WANG, J-W. CHEN, C.T.; KAO, C. H. Changes in ammonium ion content and glutamine synthetase activity in rice leaves caused by excess cadmium are a consequence of oxidative damage. Plant Growth Regulation, p. 1-7, 2000.

GONZÁLES, A.; TEZARA, W.; RENGIFO, E.; HERRERA, A. Ecophysiological responses to drought and salinity in the cosmopolitan invader Nicotiana glauca. Braz. J. Plant Physiol. vol. 24 n. 3, p. 213-222, 2012.

FERREIRA, R. G.; et al. Espécies arbóreas potenciais para a recuperação de áreas degradadas na base de operações geólogo Pedro de Moura, Coari - AM. 2006.

HAGEMAN, R. H. G.; HUCKLESBY, D. P., Nitrate reductase from higher plants. In: Methods in enzimology, New York, Academic Press, v. 17a, p. 491-503, 1971.

KAMACHI, K.; YAMAYA, T.; MAE,T.;OJIMA, K. A. Role for glutamine synthetase in remobilization of leaf nitrogen during natural senescence in rice leaves. Plant Phys, v. 96, p.411-417, 1991.

MELO, H. C. et al. Alterações anatômicas e fisiológicas em Setaria anceps Stapf ex Massey e Paspalum paniculatum L. sob condições de déficit hídrico. Hoehnea, v. 34, n. 02, p. 145-153, 2007.

MUCHOW, R. C.; CARBERRY, P. S. Designing improved plant types for the semi-arids tropics: Agronomist viewpoints. In: PENNING DE VRIES, F. W. T.; TENG, P.; METSELAAR, K. (Eds). Systems Approachs for agricultural Development. Dordrecht: Kluwer, p. 37-61, 1993.

NASCIMENTO, H. H. C.; NOGUEIRA, R. J. M. C.; SILVA, E. C.; SILVA, M. A. Análise do crescimento de mudas de jatobá (Hymenaea courbaril L.) em diferentes níveis de água no solo. Viçosa, Maio/junho. Revista árvore, vol. 35, n.3. 2011.

PAGTER, Majken; BRAGATO, Claudia; BRIX, Hans. Tolerance and physiological responses of Phragmites australis to water deficit. Aquatic Botany, v. 81, n. 4, p. 285-299, 2005

PEOPLES, M. B.; FAIZAH, A. W.; REAKASEM, B. E.; HERRIDGE, D. F. Methods for evaluating nitrogen fixation by nodulated legumes in the field. Australian Centre for International Agricultural Research, p. 76, 1989.

PINHEIRO, K.A.O., et al. Fitossociologia de uma área de preservação permanente no leste na Amazônia: indicação de espécies para recuperação de áreas alteradas. Rev. Flor.,37, 175-187, 2007.

SWAINE, M. D.; WHITMORE, T. C. On the definition of ecological species groups in tropical rain forests. Vegetation 75:81-86, 1988. 
SHANER, D.L.; BOYER, J.S. Nitrate reductase activity in maize (Zea mays L.) leaves. I. Regulation by nitrate flux. Plant Physiology, Maryland, v.58, p.499-504, 1976.

VAN DEN BERG, M.E. Ver-O-Peso: the ethnobotany of an Amazonian market. In: Prance, G.T.; Kallunki, J.A. (Eds.). Advances in Economic Botany. Ethnobotany in the Neotropics. New York Botanical Garden, Bronx, New York. p. 140-149. 1984.

WEATHERBURN, M. W. Phenol hipochlorite reaction for determination of ammonia. Analytical Chemistry, v. 39, p. 971-974, 1967. 